International Journal of Agricultural and Applied Sciences, June 2021, 2(1):68-79

https://www.agetds.com/ijaas

ISSN: 2582-8053

https://doi.org/10.52804/ijaas2021.218

Research Article

OPEN ACCESS

\title{
Soil properties among Indian Central Himalayan agroecosystems as affected by altitude and size variations
}

\author{
Charu Shahi, SS Bargali and Kiran Bargali \\ Department of Botany, DSB Campus, Kumaun University, Nainital \\ Corresponding author e-mail: charusha91@gmail.com
}

(Received: 11/12/2020; Revised: 10/04/2021; Accepted: 12/06/2021)

\begin{abstract}
The present study has been performed among Central Himalayan agroecosystems (AGEs) to analyze the changes in some physico- chemical properties of soils along four altitudes viz. very low (VLA), low (LA), mid (MA) and high altitude (HA). The AGEs were categorized into three size classes i.e. small, medium, and large based on the regional availability of landholding sizes. Results revealed that the size of the AGEs significantly affected only physical parameters of the soil while chemical parameters remain unaffected, this may be due to the regional similarity in management practices of AGEs which governed by the identical seasonal cropping patterns, local food selectivity and economic status of the peasant. The soil bulk density was recorded maximum at VLA $\left(1.00 \mathrm{~g} \mathrm{~cm}^{-3}\right)$ and decreased with increasing altitude and sizes of agroecosystem thus the correlations were significant. Water holding capacity depicted positive relation with porosity $(\mathrm{r}=0.229, \mathrm{P}<0.01)$ and $\mathrm{OC}(\mathrm{r}=0.273)$ while negative relation with silt $(\mathrm{r}=-0.172)$, bD $(\mathrm{r}=-0.221$, ) and $\mathrm{pH}(\mathrm{r}=-0.081)$. Soil nitrogen was reported highest at MA in medium sized agroecosystems, during the rainy season $(0.287 \%)$ followed by winter $(0.257 \%)$ and summer season $(0.243 \%)$. Overall maximum soil carbon stock was observed at MA $\left(41.41 \mathrm{t} \mathrm{ha}^{-1}\right)>$ HA $\left(37.85 \mathrm{t} \mathrm{ha}^{-1}\right)>\mathrm{LA}\left(33.00 \mathrm{t} \mathrm{ha} \mathrm{C}^{-1}\right)>$ VLA $\left(30.16 \mathrm{t} \mathrm{ha}^{-1}\right)$. Suitable management practices of higher altitudes reflected as the high fertility of the soil in those regions $(\mathrm{SQI}=\mathrm{HA}>\mathrm{MA}>\mathrm{LA}>\mathrm{VLA})$ which must be followed by the farm managers of lower altitudes.
\end{abstract}

Keywords: Himalayan agroecosystems, altitudes, size variations, soil properties, organic matter

\section{INTRODUCTION}

"The most meaningful indicator for the health of the land is whether the soil is being formed or lost. If soil is being lost, so too is the economic and ecological foundation on which production and conservation is based" - Christine Jones

The above quotation deeply explains the ponderability of soil conservation, particularly in the context of agroecosystems. Agroecosystem, a complex, humancentered, and three-dimensional (special natureeconomy-society) entity, plays a crucial role in human survival (Conway, 1987; Altieri et al. 2012). Agricultural ecosystems cover more than one-quarter of the global land area (approximately 50 million $\mathrm{km}^{2}$ ), as highly simplified systems (e.g., cropland, pastureland) or more complex systems (e.g., polyculture, agroforestry) with the ability to support higher biodiversity (Schroth et al. 2004). This story begins with the soil quality, which is the capacity of soil to function within ecosystem boundaries to sustain biological productivity, maintain environmental quality, and promote biological health. Thus soil has a profound effect on the temperament and productivity of a given ecosystem and the environment related to it (Spohn et al. 2016). Soil is defined as the unconsolidated mineral or organic material on the immediate surface of the Earth, which serves as a natural medium for the growth of terrestrial plants (SSSA, 2008), it is usually a sophisticated mixture of eroded rocks, mineral, decaying organic matter, water, air, and numerous microscopic decomposers (Miller, 2007). Soil quality is related to soil function and considers those attributes of soil that may be influence by management practices and have the capability to enhance or diminish the soil health (Curell et al. 2012).

Plants exploit nutrients from the soil and use them for different metabolic processes and return the nutrients through litter fall (Bhatt et al., 2017). In context of Himalayan agroecosystems, this nutrient cycling is an important process that enhances the organic matter deposition in soil which finally results the sequestration of carbon stocks (Bargali et al., 2015). During the past several decades, a significant decline in soil health has been observed worldwide due to incongruous agricultural practices and land uses (Sinha et al. 2013), about 2 billion of the 8.7 billion ha of agricultural land, permanent pastures, forests, and woodlands have been degraded. This is due to excessive and unbalanced 
inorganic chemical applications, inappropriate tillage, nutrient mining, and many other anthropogenic activities (Schmidt et al. 2011). This trend also affected to the Indian Himalayan agroecosystems consequences a solely changed cropping pattern has been observed in those areas (Shahi et al. 2019). It is well known that the excessive use of nitrogen and chemical fertilizers causes soil acidification, eutrophication, (Wang et al. 2017), and malfunctioning of microbial activities. The adverse consequences of this trend in Himalayan agroecosystems are increased erosion, decreased soil fertility, loss of biodiversity, water pollution, alteration of atmospheric and climate processes (Shahi, 2020). In recent years, soil quality has become a major concern in developing countries, where the intensification of production has become widespread. This intensification is raising concerns about the vulnerability of the productive capacity of agroecosystems caused by deteriorating soil fertility (Azam et al. 2009) and the growth of vegetation depends upon the nutrient supplying capability of the soil (Saha et al. 2018).

Table 1. Description of the study sites Altitudes

$\begin{array}{ll}\text { Altitudinal } & \begin{array}{l}\text { Geographic } \\ \text { coordinates of site } \\ \text { range }(m)\end{array}\end{array}$

Available size range of agroecosystems (ha)

Very low Up to 450

(VLA)

Lat-

$29^{\circ} 12^{\prime} 47.91^{\prime \prime} \mathrm{N}$

Long-

$79^{\circ} 29^{\prime} 19.20^{\prime \prime} \mathrm{E}$

Low $\quad 450-900 \quad$ Lat-29 $19^{\circ} 7.94^{\prime \prime} \mathrm{N} \quad 0.06-0.80$

(LA) Long-

$79^{\circ} 31^{\prime} 30.92^{\prime \prime} \mathrm{E}$

$\begin{array}{lll}\text { Mid } & 900-1600 & \text { Lat- } \\ \text { (MA) } & & 29^{\circ} 21^{\prime} 27.55^{\prime \prime} \mathrm{N}\end{array}$

$0.12-1.20$

Long-

$79^{\circ} 36^{\prime} 24.08^{\prime \prime} \mathrm{E}$

$\begin{array}{lll}\text { High } & 1600-2200 & \text { Lat- } \\ \text { (HA) } & & 29^{\circ} 23^{\prime} 39.31^{\prime \prime} \mathrm{N}\end{array}$

Long-

$79^{\circ} 39^{\prime} 48.02^{\prime \prime} \mathrm{E}$
Table 2: Method used for estimation of physico-chemical properties of soil

Properties Parameters Formulae/ Methods

Physical Texture Sand $=0.02-2.0 \mathrm{~mm}$

Silt $=0.002-0.02 \mathrm{~mm}$

Clay- $<0.002 \mathrm{~mm}$

$\mathrm{bD}$

$$
\text { Bulk density }\left(\mathrm{g} \mathrm{cm}^{-3}\right)=\frac{W(\text { weight })}{V(\text { Volume })}
$$

SMC

Soil Moisture Content (\%)

$=\frac{\text { Fresh weight of soil }- \text { Dry weight of soil }}{\text { Dry weight of soil }} \times 100$

WHC

Porosity

Chemical pH

Total Organic

Carbon

Total Nitrogen Micro Kjeldhal digestion technique

Phosphorous Using Spectrophotometer

Potassium Using Flame photometer

SQI Soil Quality

Index $S Q$ index $=\Sigma\left(X X_{\max ^{-1}}\right) n^{-1}$
Citations

Indian Standard, 1965

Misra, 1968

Jackson, 1958

Piper, 1950

Kumar, 2000

Using digital $\mathrm{pH}$ meter

Walkley and Black, 1934; Jackson, 1958 Kjeldahl 1883; Peach and Tracy, 1956

Olsen et al., 1954;

Jackson, 1958

Jackson, 1958;

Black, 1965

Mariappan et al., 2018
In this context, the present study would be beneficial to get information about the regional agroecosystem's soil properties and nutrient status. Agriculture is highly dependent on specific climate conditions and agricultural practices such as crop residue burning, puddling, intensive tillage, and the use of fertilizer also affect the climate by emitting greenhouse gases (GHGs). In a developing country like India where agriculture and forest are mainstays of people's alimentation, the maintenance and improvement of soil health and quality is a prime concern. It has now become evident that the development of better yielding varieties and crop diversity for greater food production cannot overcome poor soil quality problems, so now it has become important to monitor soil quality on landscape-level in every region of the world. The present study was undertaken with objectives to (i) evaluate the soil quality parameters under different agroecosystems and (ii) identify the effects of altitude 
and size variations on soil quality of agroecosystems in Indian Central Himalaya. This may help in the selection of an appropriate cropping pattern for a given environment in terms of its sustainability. Additionally, this study could be beneficial for the understanding of the global carbon and nutrient linking models because regional CNPK-input, soil physical properties, and soil qualities are interlinked with the global nutrient cycling.

\section{MATERIALS AND METHODS}

Study sites representing four altitudes were selected in the Nainital district of Uttarakhand state, India. At each altitude agroecosystems (AGEs) were categorized into three size classes (small, medium, and large). The general description of the study sites are given in Table 1. This study conducted during 2017-18 across all three seasons viz. rainy (July to October), winter (November to February) and summer (March to June). The very low and low altitude falls in the foothill region while the mid and high altitudes located in hilly areas, therefore site-specific climatic data was entertained for this study (Figure 1) (Climate Uttarakhand, 2018).

In this study, soil properties included five soil physical properties (texture, bulk density, soil moisture content, water holding capacity, and porosity) and five soil chemical properties $(\mathrm{pH}$, organic carbon, nitrogen, potassium, phosphorous). Samples were collected from two depths i.e., 0-15 cm (surface layer) and 15-30 cm (sub-surface layer) from study sites with a random sampling method. The soil indicator values were determined for each soil sample annually (4 altitudes $\times$ 3 size classes $\times 3$ replicates $\times 2$ depths $=72$ samples) for physical properties and seasonally $(4$ altitudes $\times 3$ seasons $\times 3$ size classes $\times 3$ replicates $\times 2$ depths $=216$ samples) for chemical properties using standard methods (Table 2).

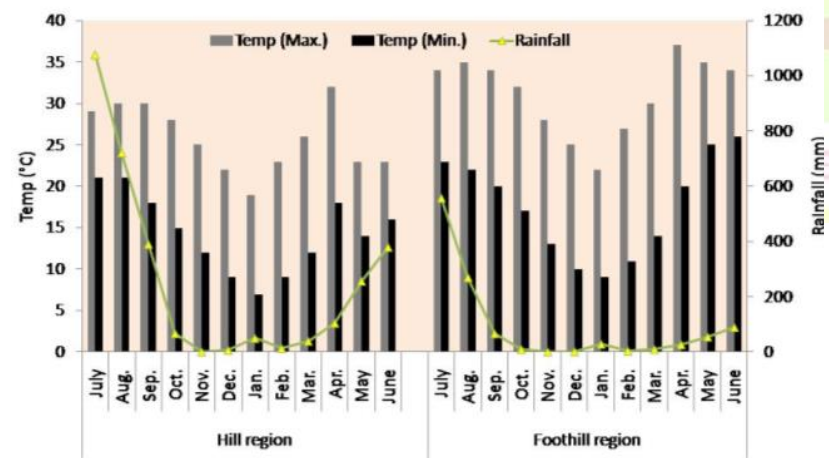

Figure 1. Climatic data during study period

(Source: https://en.climate-data.org/asia/india/uttarakhand-763/.)

\section{RESULTS AND DISCUSSION}

\section{Physical Properties of soil}

At all the sites, sand particles were reported higher than silt and clay particles (except the small agroecosystem at VLA). Percentage of sand particles ranged from 37.58 to $55.53 \%$ in the surface layer and 55.53 to 57.12 $\%$ in the sub-surface layer of soils and increased with increasing altitude and depth. Silt particles differed from 18.52 to $25.90 \%$ and the proportion of clay particles varied from 19.40 to $40.13 \%$ in the surface layer of soils (Table 3 ).

Maximum bulk density (bD) of soil was $1.06 \mathrm{~g} \mathrm{~cm}^{-3}$ in sub-surface layer of small agroecosystems (AGEs) of LA whereas minimum bD was $0.80 \mathrm{~g} \mathrm{~cm}^{-3}$ on the surface layer of large AGEs of HA. The highest soil porosity (69.10\% at surface layer) was reported in large AGEs of HA while lowest soil porosity $(59.36 \%)$ was reported in the sub-surface layer of small AGEs of LA (Table 3).

Maximum SMC (14.86 \%) was recorded in the subsurface layer of small AGEs of MA while minimum percentage of SMC (4.50\%) was observed in surface layer of large AGEs of MA. Water holding capacity (WHC) ranged between $31 \%$ and $52 \%$ and was reported maximum in sub-surface layer of small AGEs at MA whereas lowest WHC was reported in surface layer of large AGEs at VLA (Table 3).

Effect of Altitudes, size of AGEs and Soil Depth on Physical Properties of soil:

In the present study, altitude showed a significant effect on the soil's physical properties (Table 4). Soil texture showed a clear difference with the altitudinal differences. Sand had a significant correlation $(\mathrm{P}<0.01)$ with altitude as it increases with increasing altitude (Figure 2a), while the silt $(\mathrm{r}=-0.378, \mathrm{P}<0.01)$ and clay $(\mathrm{r}=-0.054, \mathrm{NS})$ particles showed a negative correlation with altitude (Table 7). Wani et al. (2017) reported a similar observation for the pear orchards in Pulwama district of South Kashmir. Cropping patterns and management practices affect the soil properties which in turn affect the fertility status of a field and introduce some variations in soil texture (Yao et al., 2010). The soil bulk density of the area showed a significant correlation $(\mathrm{P}<0.01)$ and variation with altitude (Figure 2a; Table 4). Relatively higher soil bulk density was observed in the soils of lower altitude as compared to those of higher altitude sites. Murphy et al. (2004) suggested that the compaction of soil particles in forest land and other land-use systems results in higher bulk densities. The relatively higher bulk density soils of the lower altitude might be attributed to the existence of relatively lower OM accumulation in the low altitude agroecosystems. In connection with this, the overall bulk density showed a significant negative correlation with soil OM ( $\mathrm{r}=-0.321$; Table 7$)$. Porosity showed a reverse trend indicating that soils with high OM accumulation are higher in percent pore space regardless of the number of soil particles in the soil and results in lower bulk density whereas the soils with lower OM are lower in percent pore space and results in higher bulk density. Sanjay et al. (2010) also pointed out that the lower bulk density at top altitudes is a good indication of soils that have occupied the coarser structure of organic matter and enriches the spaces by soil organic carbon. 
Table 3. Soil physical parameters in different altitudes and sizes

\begin{tabular}{|c|c|c|c|c|c|c|c|c|c|}
\hline \multirow{2}{*}{$\begin{array}{l}\text { Size } \\
\text { Altitude }\end{array}$} & $\begin{array}{l}\text { Depth } \\
(\mathrm{cm})\end{array}$ & $\begin{array}{l}\text { Soil texture } \\
\text { Sand (\%) }\end{array}$ & Silt (\%) & Clay (\%) & $\left(\mathrm{g} \mathrm{cm}^{-3}\right)$ & $\begin{array}{l}\text { SMC } \\
(\%)\end{array}$ & $\begin{array}{l}\text { WHC } \\
(\%)\end{array}$ & $\begin{array}{l}\text { Porosity } \\
(\%)\end{array}$ & Soil type \\
\hline & & & & VLA & & & & & \\
\hline \multirow[t]{2}{*}{$S$} & $0-15$ & $37.58 \pm 1.42$ & $22.29 \pm 2.89$ & $40.13 \pm 3.84$ & $1.01 \pm 0.04$ & $10.02 \pm 1.52$ & $35.33 \pm 0.67$ & $61.67 \pm 1.30$ & Clay \\
\hline & $15-30$ & $37.25 \pm 2.39$ & $23.69 \pm 2.43$ & $39.05 \pm 4.78$ & $1.04 \pm 0.03$ & $11.70 \pm 1.85$ & $38.67 \pm 0.88$ & $60.13 \pm 1.11$ & Clay \\
\hline \multirow{2}{*}{ M } & $0-15$ & $39.43 \pm 5.26$ & $25.55 \pm 2.39$ & $35.02 \pm 7.15$ & $0.93 \pm 0.01$ & $7.96 \pm 1.14$ & $34.67 \pm 3.18$ & $64.10 \pm 0.56$ & Clay loam \\
\hline & $15-30$ & $40.77 \pm 5.01$ & $25.41 \pm 2.95$ & $33.82 \pm 7.43$ & $0.95 \pm 0.01$ & $9.72 \pm 1.64$ & $37.00 \pm 4.72$ & $63.59 \pm 0.78$ & Clay loam \\
\hline \multirow{3}{*}{$\mathrm{L}$} & $0-15$ & $48.88 \pm 1.16$ & $24.51 \pm 0.67$ & $26.61 \pm 0.65$ & $1.02 \pm 0.01$ & $5.15 \pm 1.09$ & $31.00 \pm 3.21$ & $61.28 \pm 0.33$ & Loam \\
\hline & $15-30$ & $52.09 \pm 1.82$ & $24.66 \pm 2.31$ & $23.25 \pm 2.68$ & $1.04 \pm 0.02$ & $6.84 \pm 0.94$ & $32.33 \pm 3.33$ & $61.41 \pm 0.89$ & Loam \\
\hline & & & & LA & & & & & \\
\hline \multirow[t]{2}{*}{$S$} & $0-15$ & $40.05 \pm 5.05$ & $23.20 \pm 2.54$ & $37.45 \pm 6.97$ & $1.03 \pm 0.01$ & $10.63 \pm 3.27$ & $43.00 \pm 0.58$ & $60.90 \pm 0.13$ & Clay loam \\
\hline & $15-30$ & $42.21 \pm 6.07$ & $22.20 \pm 3.19$ & $36.05 \pm 7.67$ & $1.06 \pm 0.02$ & $12.19 \pm 3.17$ & $44.00 \pm 2.31$ & $59.36 \pm 0.68$ & Clay loam \\
\hline \multirow{2}{*}{ M } & $0-15$ & $50.22 \pm 8.09$ & $21.19 \pm 0.63$ & $28.59 \pm 8.09$ & $0.99 \pm 0.02$ & $9.65 \pm 2.47$ & $39.33 \pm 0.88$ & $62.05 \pm 0.68$ & Loam \\
\hline & $15-30$ & $50.34 \pm 8.73$ & $21.74 \pm 1.27$ & $27.92 \pm 7.63$ & $1.00 \pm 0.02$ & $11.65 \pm 1.95$ & $42.00 \pm 0.58$ & $61.67 \pm 0.46$ & Loam \\
\hline \multirow{3}{*}{ L } & $0-15$ & $49.08 \pm 1.34$ & $23.38 \pm 0.53$ & $23.38 \pm 0.81$ & $0.89 \pm 0.01$ & $5.31 \pm 1.17$ & $42.33 \pm 0.89$ & $65.77 \pm 0.22$ & Loam \\
\hline & $15-30$ & $50.09 \pm 1.29$ & $24.01 \pm 0.29$ & $25.89 \pm 1.02$ & $0.92 \pm 0.00$ & $7.58 \pm 1.14$ & $45.00 \pm 0.58$ & $64.49 \pm 0.13$ & Loam \\
\hline & & & & MA & & & & & \\
\hline \multirow[t]{2}{*}{ v } & $0-15$ & $55.53 \pm 1.90$ & $25.25 \pm 0.71$ & $19.40 \pm 1.74$ & $0.96 \pm 0.05$ & $11.40 \pm 2.11$ & $50.67 \pm 1.45$ & $62.95 \pm 1.99$ & Loam \\
\hline & $15-30$ & $57.12 \pm 2.07$ & $25.09 \pm 2.01$ & $17.78 \pm 1.35$ & $0.99 \pm 0.05$ & $14.86 \pm 3.48$ & $52.00 \pm 1.73$ & $61.92 \pm 1.93$ & Loam \\
\hline \multirow{2}{*}{ M } & $0-15$ & $52.70 \pm 3.47$ & $24.97 \pm 0.77$ & $22.32 \pm 3.94$ & $0.91 \pm 0.04$ & $7.44 \pm 2.32$ & $42.00 \pm 0.57$ & $65.13 \pm 1.51$ & Loam \\
\hline & $15-30$ & $55.37 \pm 3.12$ & $24.96 \pm 1.24$ & $19.67 \pm 3.42$ & $0.92 \pm 0.04$ & $8.03 \pm 1.88$ & $40.33 \pm 3.93$ & $64.49 \pm 1.63$ & Loam \\
\hline \multirow{3}{*}{ 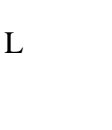 } & $0-15$ & $49.31 \pm 1.60$ & $25.90 \pm 0.82$ & $24.78 \pm 1.07$ & $0.90 \pm 0.01$ & $4.50 \pm 1.58$ & $42.00 \pm 0.57$ & $65.26 \pm 0.13$ & Loam \\
\hline & $15-30$ & $48.69 \pm 3.62$ & $25.91 \pm 1.32$ & $25.40 \pm 4.12$ & $0.96 \pm 0.01$ & $6.58 \pm 1.84$ & $43.67 \pm 1.45$ & $63.21 \pm 0.46$ & Loam \\
\hline & & & & HA & & & & & \\
\hline & $0-15$ & $42.43 \pm 0.93$ & $18.52 \pm 0.48$ & $39.05 \pm 1.35$ & $0.82 \pm 0.02$ & $4.71 \pm 0.78$ & $45.67 \pm 0.88$ & $68.46 \pm 0.58$ & Clay \\
\hline & $15-30$ & $42.80 \pm 0.37$ & $18.23 \pm 0.22$ & $38.97 \pm 0.14$ & $0.84 \pm 0.01$ & $7.89 \pm 1.34$ & $43.67 \pm 0.88$ & $67.95 \pm 0.56$ & Clay \\
\hline \multirow{2}{*}{ M } & $0-15$ & $43.15 \pm 2.35$ & $18.52 \pm 51$ & $38.33 \pm 2.27$ & $0.86 \pm 0.03$ & $7.01 \pm 1.14$ & $46.33 \pm 1.45$ & $67.05 \pm 1.22$ & Clay \\
\hline & $15-30$ & $41.93 \pm 0.89$ & $19.01 \pm 0.31$ & $39.06 \pm 0.31$ & $0.88 \pm 0.04$ & $12.34 \pm 3.81$ & $49.00 \pm 4.04$ & $66.15 \pm 1.55$ & Clay \\
\hline & $0-15$ & $51.31 \pm 0.89$ & $21.72 \pm 0.86$ & $26.97 \pm 0.14$ & $0.80 \pm 0.01$ & $4.13 \pm 1.33$ & $38.67 \pm 2.33$ & $69.10 \pm 0.46$ & Loam \\
\hline & $15-30$ & $51.98 \pm 1.66$ & $22.30 \pm 0.87$ & $25.72 \pm 0.96$ & $0.83 \pm 0.01$ & $7.56 \pm 0.65$ & $40.33 \pm 3.71$ & $68.21 \pm 0.34$ & Loam \\
\hline
\end{tabular}

Table 4. Analysis of variance (ANOVA) of soil physical parameters

$\begin{array}{lllllllll}\text { Parameters } & \text { df } & \text { Sand } & \text { Silt } & \text { Clay } & \text { bD } & \text { SMC } & \text { WHC } & \text { Porosity } \\ \text { Altitude } & 3 & 1052^{* *} & 328.44^{* *} & 1862.11^{* *} & 0.308^{* *} & 46.74^{*} & 1163.37 * * & 431.28^{* *} \\ \text { Size } & 2 & 501.36^{* *} & 60.06^{*} & 1219.35^{* *} & 0.039^{*} & 385.54 * * & 403.62^{* *} & 59.13^{*} \\ \text { Depth } & 1 & 37.83 & 2.01 & 52.78 & 0.038^{*} & 315.88^{* *} & 108.37 & 42.48^{*}\end{array}$

$* *=$ significant at $.001 ; *=$ at .05 level; $\mathrm{df}=$ degree of freedom; $\mathrm{bD}=$ bulk density; $\mathrm{SMC}=$ soil moisture content;

$\mathrm{WHC}=$ water holding capacity

Soil moisture content (SMC) and water holding capacities (WHC) of soils were also significantly affected by the altitudes (Table 4). The water runoff from high altitudes must be responsible for lower SMC at this altitude and water retention at the foothill region; it can be one of the reasons behind higher SMC at VLA. Besides this point of view, the irrigation facilities at mid and lower altitudes must be taken into account while dealing with SMC.

Average values of sand $(50.17 \%)$ and silt $(24.02 \%)$ were found highest in large AGEs and significantly decreased with decreasing size of AGEs whereas the clay $(33.96 \%)$ particles were reported highest in small AGEs and significantly decreased with increasing size of AGEs (Figure 2b). Similar findings were also reported by Vibhuti (2018) for different sized home gardens. Small AGEs were reported with maximum values of bD $\left(0.97 \mathrm{~g} \mathrm{~cm}^{-3}\right)$, SMC (10.42\%), and WHC $(44.12 \%)$, and these values significantly decreased with increasing size of AGEs. All physical properties showed a significant correlation with the size of AGEs (Table 7).

Sand and silt percentages were not significant while the soil bD, SMC, and porosity were statistically significant with the soil depth. Sand $(47.64 \%)$ and silt $(23.06 \%)$ percentages were higher in the deeper layer while the clay $(30.49 \%)$ percentage was higher in the upper layer (Figure 2c). While studying the Quercus leucotrichophora forest in Pauri Garhwal, Semwal (2006) reported the value of sand, silt, and clay particles ranged from 24.10 to $42.10 \%, 3.80$ to 16.80 $\%$ and 51.70 to $72.10 \%$, respectively. 

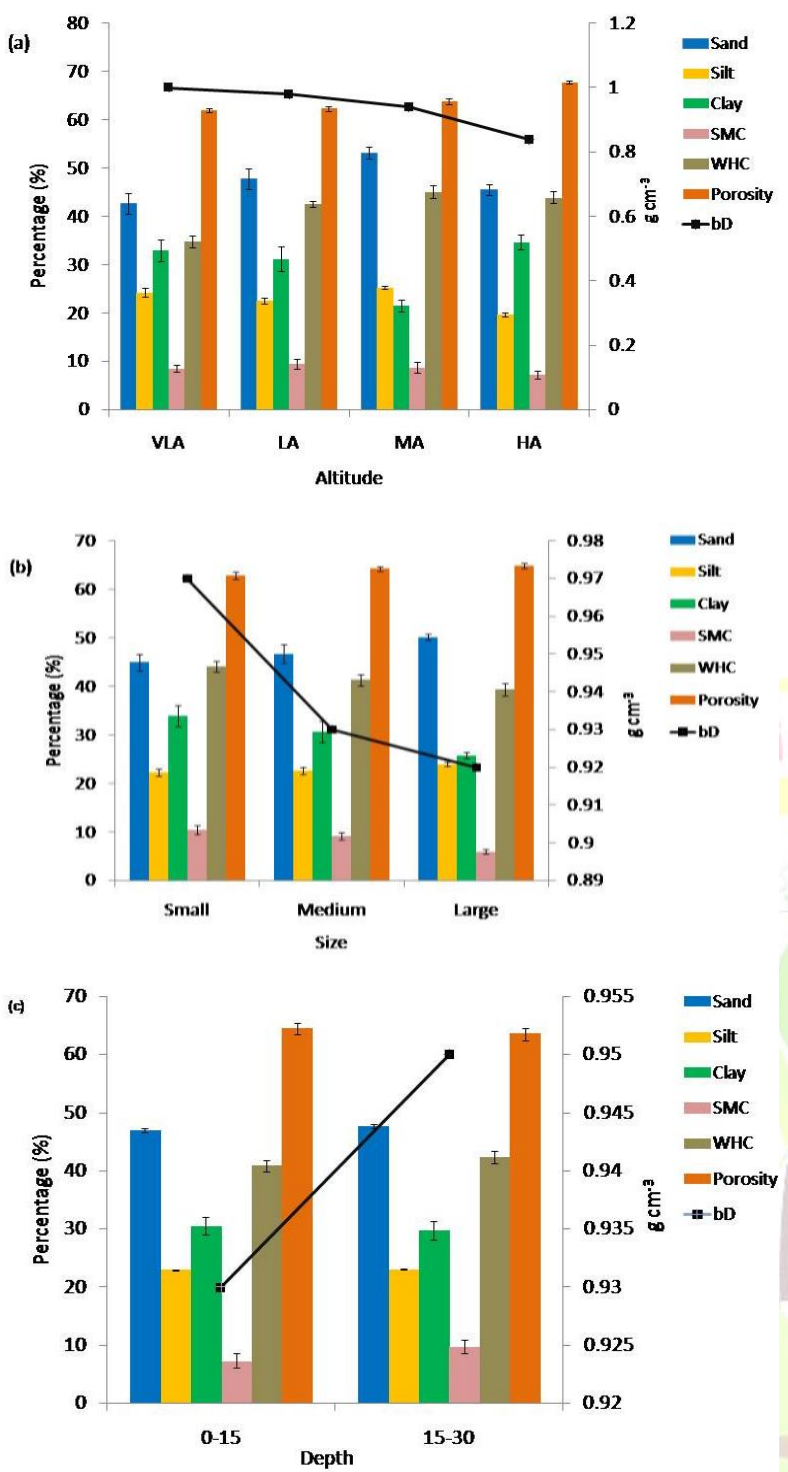

Figure 2. Effect of (a) altitude, (b) size and (c) depth on physical properties of soil.

VLA $=$ very low altitude; $L A=$ low altitude; $M A=$ mid altitude; $\mathrm{HA}=$ high altitude

\section{Chemical Properties of soil}

In the rainy season, highest $\mathrm{pH}$ values (7.7) were observed in large AGEs of LA while the lowest $\mathrm{pH}$ value was recorded during the summer season in small AGEs (6.2 in upper and 6.53 in lower depths) of HA. The soil of LA showed alkaline nature as it was observed with the highest $\mathrm{pH}$ values in all three seasons (Figure 3).

Soil organic carbon for surface $(4.12 \%)$ and subsurface $(3.70 \%)$ layer was recorded maximum in small AGEs of HA, during the rainy season, Whereas it was recorded minimum during summer season for surface $(0.87 \%)$ and sub-surface $(0.85 \%)$ layer in large AGEs of VLA (Figure 4).

Soil total nitrogen (TN) was observed highest during rainy season for surface $(0.398 \%)$ layer in medium sized AGEs at MA. During all the three seasons minimum soil TN percentages were recorded at VLA in both depths. Maximum soil phosphorous was reported during the rainy season for surface $(0.0125 \%)$ and subsurface $(0.0105 \%)$ layer in small AGEs of HA whereas minimum soil $\mathrm{P}$ was recorded during the winter season for surface $(0.0047 \%)$ and sub-surface $(0.0040 \%)$ layer in large AGEs of VLA (Table 5). Soil potassium was observed highest during the winter season in the surface layer $(0.0757 \%)$ of medium agroecosystems at $\mathrm{HA}$ while lowest soil $\mathrm{K}$ was estimated during the rainy season in the sub-surface layer $(0.0073 \%)$ of small agroecosystems of LA (Table 5).

Effect of Altitudes, size of AGEs, Soil Depths and Seasons on Chemical Properties of Soil:

The average soil $\mathrm{pH}$ value ranged between 6.71 (MA) and 7.47 (LA) and indicates slightly acidic to slightly alkaline nature as per the $\mathrm{pH}$ rating category suggested by Dekker (1999). These values were higher than the $\mathrm{pH}$ values reported for oak and pine forests of Western Himalaya (Joshi and Negi 2015) indicating that the forest soils were less acidic than the soils of agroecosystems. The significantly high $\mathrm{pH}$ of soils from the forest land of the area might be attributed to the ameliorating effect of the high accumulation of organic matter at the surface. Soil $\mathrm{pH}$ was higher in the soils of lower altitude as compared to those of higher altitude sites. Ololade et al. (2010) stated that the altitudinal variations in $\mathrm{pH}$ occur due to the variable use of fertilizers and chemicals in the fields. Soil TN was observed maximum at MA whereas all other chemical parameters (soil P, K, OM, and OC) were highest at HA (Table 5). A similar pattern was observed by many researchers (Morisada et al. 2004; Su et al. 2006; Saha et al. 2018). Soil OM content of the lower elevation site (VLA) was found to be reduced by about $33.12 \%$ and $35.04 \%$ than the MA and HA, respectively. Atmospheric temperature is the main climatic variable that controls soil nutrient status. Cooler temperature, higher precipitation in the form of snowfall and high acidity at high altitude than lower altitudes decrease the rate of decomposition (Jose and Bardhan 2012; Bargali et al. 2015) and mineralization of soil organic matter that makes a higher accumulation of nutrients ( $\mathrm{He}$ et al. 2016). Usman et al. (2000) also reported that soil OM accumulation increases with increasing precipitation and decreases with increasing temperature. Usually, lower altitudes have a higher temperature than the high altitude thus this relatively high temperature resulted in increased soil OM decomposition and mineralization thereby decreases its accumulation (Groffman et al. 2009; Zhang et al. 2012).

The soil organic carbon (SOC) also showed an increasing trend with increasing altitude indicating that the change in altitudinal gradients can also influence SOC by controlling soil water balance. All the chemical properties of soils significantly differed at the $\mathrm{P}<0.001$ level of significance with altitudinal variations (Table 6). A positive correlation between SOC and altitude ( $\mathrm{r}=$ $0.439 ; \mathrm{P}<0.01)$ as reported in the present study was 
similar to the study of Bargali et al. (2018) for forest soils. The positive correlation between TN, P, K, and altitude (Table 7) may be associated with the variability of soil $\mathrm{OM}$ with an altitudinal gradient.

ANOVA showed that chemical properties remain unaffected by the size of the agroecosystems. Across the size classes, the $\mathrm{pH}$ values ranged from 7.00 (small AGEs) to 7.05 (medium AGEs) (Table 6). Adigun et al. (2008) supported the low variability of soil $\mathrm{pH}$ in agricultural fields and suggested that the application of fertilizers in the fields is responsible for low variations. All the observed soil nutrients showed a decreasing trend with increasing AGEs size though the differences were not significant (Table 7). However, Jaman et al. (2016) observed that the size of the home garden is a major factor that affects the Soil OC content per unit area and decreased with increasing home garden sizes. The lower nutrients in soils of the large agroecosystems could be attributed to the continuous process of cultivation and removal by crop produce and residues. All the observed chemical properties of the soil showed an insignificant correlation with the size of AGEs (Table 7). A phenomenon, well demonstrated by the study of many scientists (Takata et al. 2007; Rhanor 2013) stated that the land use and cover changes in elevated ecosystems play a crucial role in regulating soil organic carbon and nitrogen stocks. Additionally, the spatial patterns for those changes are driven by topographic and ecological differences resulting from altitudinal macro and microclimates.

Depth wise chemical properties (soil P, K, OM, and OC) showed decrement towards lower depth but these differences were statistically not significant (Table 5 and 6). Shah et al. (2013) highlighted that the greater accumulation of soil nutrients on the surface is due to the greater incorporation of leaf litter on it. These factors are consecutively influenced by land-use and residue management (Burton et al. 2007). According to Gairola et al. (2012) and Garten et al. (1999), the vegetation of an area poses a great effect up to a significant level, on the chemical properties of soil.

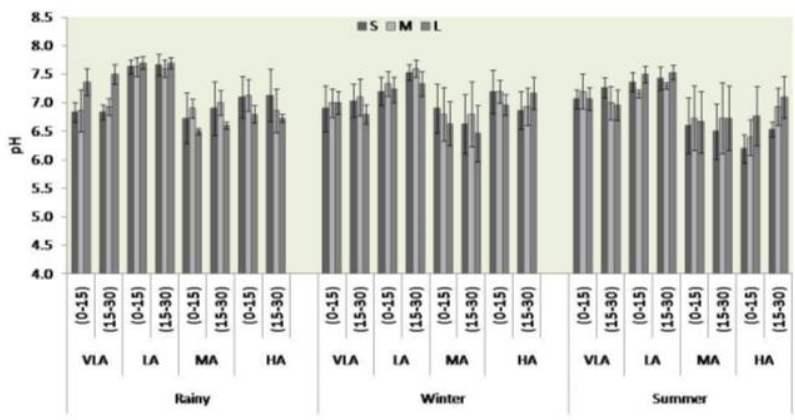

Figure 3. Seasonal $\mathrm{pH}$ values along altitudes and size classes. VLA= very low altitude; $\mathrm{LA}=$ low altitude; $\mathrm{MA}=$ mid altitude; $\mathrm{HA}=$ high altitude; $\mathrm{S}=$ small; $\mathrm{M}=$ medium; $\mathrm{L}=$ large
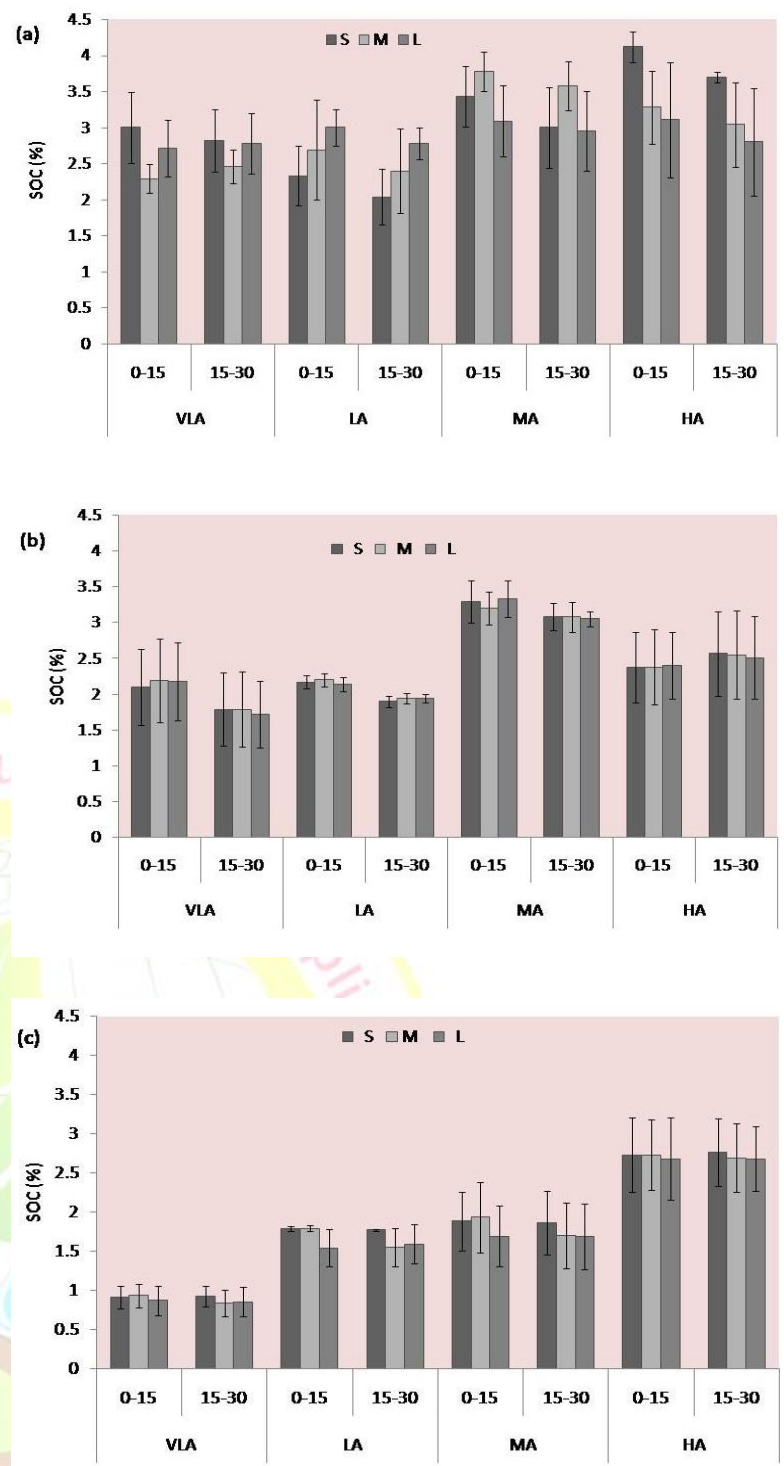

Figure 4. Seasonal soil organic carbon SOC (\%) along altitudes and across all sizes. (a) during rainy (b) winter (c) summer season. VLA= very low altitude; $L A=$ low altitude; $\mathrm{MA}=$ mid altitude; $\mathrm{HA}=$ high altitude; $\mathrm{S}=$ small; $\mathrm{M}=$ medium; $\mathrm{L}=$ large

ANOVA showed that the seasonal variations in chemical properties were significant at $\mathrm{P}<0.001$ and $\mathrm{P}<0.05$ significance, except soil $\mathrm{pH}$. It was reported that soil TN was highest during the rainy season $(0.287 \%)$ followed by winter $(0.257 \%)$ and summer season $(0.243 \%)$. A similar observation on the seasonal pattern was also reported by Saha et al. (2018). Soil P has recorded a minimum $(0.0058 \%)$ and soil $\mathrm{K}$ was recorded maximum $(0.030 \%)$ percentage during the winter season. Total nitrogen $(\mathrm{r}=-0.278)$, soil organic matter $(r=-0.525)$ and soil organic carbon $(r=-0.525)$ showed significant correlation with season while other properties showed insignificant correlation (Table 7). 
Table 5. Effect of season, altitude, size and depth on chemical properties of soil

\begin{tabular}{lllllll}
\hline Attributes & $\mathrm{pH}$ & $\mathrm{TN}(\%)$ & $\mathrm{P}(\%)$ & $\mathrm{K}(\%)$ & $\mathrm{OM}(\%)$ & $\mathrm{OC}(\%)$ \\
\hline Altitude & & & & & \\
Very low & $7.04 \pm 0.05$ & $0.207 \pm 0.007$ & $0.0052 \pm 0.0001$ & $0.009 \pm 0.001$ & $3.17 \pm 0.22$ & $1.84 \pm 0.13$ \\
Low & $7.47 \pm 0.04$ & $0.252 \pm 0.004$ & $0.0060 \pm 0.0001$ & $0.010 \pm 0.001$ & $3.59 \pm 0.14$ & $2.09 \pm 0.08$ \\
Mid & $6.71 \pm 0.09$ & $0.298 \pm 0.009$ & $0.0071 \pm 0.0002$ & $0.027 \pm 0.002$ & $4.74 \pm 0.21$ & $2.75 \pm 0.12$ \\
High & $6.89 \pm 0.07$ & $0.291 \pm 0.008$ & $0.0085 \pm 0.001$ & $0.044 \pm 0.003$ & $4.88 \pm 0.21$ & $2.84 \pm 0.12$ \\
Size & & & & & \\
Small & $7.00 \pm 0.07$ & $0.262 \pm 0.007$ & $0.0067 \pm 0.0001$ & $0.024 \pm 0.002$ & $4.18 \pm 0.19$ & $2.43 \pm 0.11$ \\
Medium & $7.05 \pm 0.06$ & $0.265 \pm 0.007$ & $0.0066 \pm 0.0001$ & $0.023 \pm 0.002$ & $4.09 \pm 0.19$ & $2.37 \pm 0.11$ \\
Large & $7.03 \pm 0.06$ & $0.259 \pm 0.008$ & $0.0069 \pm 0.0001$ & $0.021 \pm 0.002$ & $4.02 \pm 0.18$ & $2.34 \pm 0.10$ \\
Depth & & & & & \\
0-15 & $7.01 \pm 0.05$ & $0.26 \pm 0.006$ & $0.0070 \pm 0.0001$ & $0.0239 \pm 0.002$ & $4.22 \pm 0.16$ & $2.45 \pm 0.09$ \\
15-30 & $7.05 \pm 0.05$ & $0.26 \pm 0.006$ & $0.0064 \pm 0.0002$ & $0.0217 \pm 0.001$ & $3.97 \pm 0.15$ & $2.31 \pm 0.08$ \\
Season & & & & & \\
Rainy & $7.11 \pm 0.61$ & $0.287 \pm 0.008$ & $0.0072 \pm 0.0001$ & $0.019 \pm 0.001$ & $5.10 \pm 0.17$ & $2.96 \pm 0.09$ \\
Winter & $7.03 \pm 0.06$ & $0.257 \pm 0.004$ & $0.0058 \pm 0.0001$ & $0.030 \pm 0.003$ & $4.15 \pm 0.15$ & $2.41 \pm 0.08$ \\
Summer & $6.95 \pm 0.07$ & $0.243 \pm 0.009$ & $0.0072 \pm 0.0001$ & $0.019 \pm 0.002$ & $3.04 \pm 0.16$ & $1.76 \pm 0.09$ \\
\hline Mean \pm SE & $7.03 \pm 0.04$ & $0.26 \pm 0.004$ & $0.0067 \pm 0.0001$ & $0.023 \pm 0.001$ & $4.09 \pm 0.11$ & $2.38 \pm 0.06$ \\
\hline TN= Total nitrogen; P= phosphorous; K= potassium; OM= organic matter; OC= organic carbon & \\
\cline { 1 - 3 }
\end{tabular}

Table 6. Analysis of variance (ANOVA) of soil chemical parameters

\begin{tabular}{llllllll}
\hline Parameters & df & $\mathrm{pH}$ & $\mathrm{TN}$ & $\mathrm{P}$ & $\mathrm{K}$ & $\mathrm{OM}$ & $\mathrm{OC}$ \\
\hline Season & 2 & $0.48^{\mathrm{n}}$ & $0.036^{* *}$ & $0.0001^{*}$ & $0.003^{* *}$ & $76.82^{* *}$ & $25.95^{* *}$ \\
Altitude & 3 & $5.65^{* *}$ & $0.094^{* *}$ & $0.0001^{* *}$ & $0.014^{* *}$ & $38.77^{* *}$ & $13.11^{* *}$ \\
Size & 2 & 0.04 & 0.001 & 0.0001 & 0.000 & 0.48 & 0.16 \\
Depth & 1 & 0.09 & 0.002 & 0.0001 & 0.000 & 3.19 & 1.08 \\
\hline
\end{tabular}

\section{Correlations}

Bulk density showed a positive correlation with depth and SMC, whereas it showed a negative correlation with altitudes and size. The increasing trend in soil porosity with altitude may be attributed to the compaction of soil finer particles and the decreasing trend in organic matter content (Garhwal et al. 2013) and bulk density as well. WHC depicted positive relation with porosity $(\mathrm{r}=0.229, \mathrm{P}<0.01)$ and $\mathrm{OC}(\mathrm{r}=$ $0.273, \mathrm{P}<0.01)$ while negative relation with silt $(\mathrm{r}=-$ $0.172, \mathrm{P}<0.05), \mathrm{bD}(\mathrm{r}=-0.221, \mathrm{P}<0.01)$ and $\mathrm{pH}(\mathrm{r}=-$ $0.081)$. Similar findings were also documented by Upadhyaya et al. (2003) and by Paudel and Sah (2003). All chemical nutrients (TN, P, K, OM, and OC) were positively correlated with each other. $\mathrm{OM}$ and $\mathrm{OC}$ showed significant negative correlation with $\mathrm{bD}(\mathrm{r}=$ $0.321, \mathrm{P}<0.01)$ and significant positive correlation with porosity $(r=0.311, P<0.01)$. This is in agreement with Chaudhari et al. (2013) and Panthi (2010) on the other hand Keller and Håkansson (2009) also stated that bulk density decreased with high OM levels. This indicates that organic matter increases with decreasing bulk density and it is an important character of the soil, which is required for proper augmentation of the plant. $\mathrm{OM}$ and $\mathrm{OC}$ depicted significant positive correlation with $\mathrm{TN}, \mathrm{P}$, and $\mathrm{K}$, this observation was supported by the statement of Tsozué et al. 2015, who suggested that the high soil $\mathrm{OM}$ increases total $\mathrm{N}$ availability (Table 7).

Principal Component Analysis (PCA) of all soil parameters

PCA was done with the whole 13 soil quality indicators along with altitude and size variations, in which three principal components were showed the eigenvalues as more than one (Figure 5). Those components were responsible for $87.45 \%$ of the total variability. The first component was accounted for $54.42 \%$ as the most reliable component (PC1) and the maximum loadings were found with OC, OM, K, P, TN, and bD (Table 8). $\mathrm{PC} 1=0.963(\mathrm{OC})+0.963(\mathrm{OM})+0.937(\mathrm{~K})+0.924(\mathrm{P})$ $+0.905(\mathrm{TN})$

The second component (PC2) contributed about 20.59 $\%$ of the total relationship and the highest loadings were found with clay, sand, and silt (Figure 6)

$\mathrm{PC} 2=0.882$ (clay) +0.817 (Sand) +0.709 (Silt).................................. 
The PCA axis 1 was related to active sites and the PCA axis 2 represented the active variables.

$\mathrm{PC} 3=0.731 \quad(\mathrm{SMC})+0.673 \quad$ (WHC) (Table 8)

The PCA axis 1 was related to active sites and the PCA axis 2 represented the active variables. PCs analysis clearly showed the formation of three groups, based on similar soil properties along with altitude and sizes. In which VLA and LA grouped and mentioned the similarity between these two altitudes but the large agroecosystems of very low altitudes (VLAL) showed the least relation with other attributes, which was denoted as a supplementary variable (Figure 6).

Table 7. Correlation matrix among all soil parameters

\begin{tabular}{|c|c|c|c|c|c|c|c|c|c|c|c|c|c|c|c|c|c|}
\hline & Altitude & Size & Season & Depth & Sand & Silt & Clay & $\mathrm{bD}$ & SMC & WHC & Porosity & $\mathrm{pH}$ & $\mathrm{TN}$ & $\mathrm{P}$ & K & OM & OC \\
\hline \multicolumn{18}{|c|}{ Altitude 1} \\
\hline Size & 0.000 & 1 & & & & & & & & & & & & & & & \\
\hline Season & 0.000 & 0.000 & 1 & & & & & & & & & & & & & & \\
\hline Depth & 0.000 & 0.000 & 0.000 & 1 & & & & & & & & & & & & & \\
\hline Sand & $0.204^{* *}$ & $0.274 * *$ & 0.000 & 0.054 & 1 & & & & & & & & & & & & \\
\hline Silt & $-0.378 * *$ & $0.213^{* *}$ & 0.000 & 0.029 & $0.143^{*}$ & 1 & & & & & & & & & & & \\
\hline Clay & -0.054 & $-0.352^{* *}$ & 0.000 & -0.052 & $-0.891 * *$ & $-0.497 * *$ & 1 & & & & & & & & & & \\
\hline $\mathrm{bD}$ & $-0.724 * *$ & $-0.209 * *$ & 0.000 & $0.155^{*}$ & -0.113 & $0.275^{* *}$ & 0.055 & 1 & & & & & & & & & \\
\hline SMC & -0.128 & $-0.456^{* *}$ & 0.000 & $0.302 * *$ & -0.050 & 0.061 & 0.113 & $0.421 * *$ & 1 & & & & & & & & \\
\hline WHC & $0.546^{* *}$ & $-0.315^{* *}$ & 0.000 & 0.116 & $0.261 * *$ & $-0.172 *$ & $-0.135^{*}$ & $-0.221 * *$ & $0.219 * *$ & 1 & & & & & & & \\
\hline Porosity & $0.708 * *$ & $0.219^{* *}$ & 0.000 & $-0.138 *$ & 0.092 & $-0.280 * *$ & -0.038 & $-0.964 * *$ & $-0.433^{* *}$ & $0.229 * *$ & 1 & & & & & & \\
\hline $\mathrm{pH}$ & $-0.241 * *$ & 0.023 & -0.118 & 0.036 & -0.073 & -0.029 & 0.118 & $0.185^{* *}$ & 0.039 & -0.081 & $-0.156^{*}$ & 1 & & & & & \\
\hline $\mathrm{TN}$ & $0.513^{* *}$ & -0.018 & $-0.278^{* *}$ & -0.052 & $0.144^{*}$ & -0.089 & -0.108 & $-0.320^{* *}$ & -0.034 & $0.304^{* *}$ & $0.305 * *$ & $-0.154 *$ & 1 & & & & \\
\hline $\mathrm{P}$ & $0.406^{* *}$ & 0.018 & 0.004 & -0.102 & 0.001 & $-0.190 * *$ & 0.031 & $-0.327^{* *}$ & $-0.174^{*}$ & 0.128 & $0.330 * *$ & 0.045 & $0.407 * *$ & 1 & & & \\
\hline K & $0.678 * *$ & -0.065 & 0.010 & -0.057 & 0.011 & $-0.302 * *$ & 0.065 & $-0.518 * *$ & -0.125 & $0.252 * *$ & $0.515^{* *}$ & -0.004 & $0.336^{* *} *$ & $0.326^{* *}$ & 1 & & \\
\hline $\mathrm{OM}$ & $0.439 * *$ & -0.041 & $-0.525^{* *}$ & -0.076 & 0.133 & $-0.160^{*}$ & -0.067 & $-0.321 * *$ & -0.043 & $0.273^{*} *$ & $0.311 * *$ & -0.038 & $0.664^{* * *}$ & $0.373 * *$ & $0.336^{* *}$ & 1 & \\
\hline $\mathrm{OC}$ & $0.439 * *$ & -0.041 & $-0.525^{* *}$ & -0.076 & 0.133 & $-0.160 *$ & -0.067 & $-0.321 * *$ & -0.043 & $0.273^{* *}$ & $0.311 * *$ & -0.038 & $0.664^{* *}$ & $0.373^{* *}$ & $0.337 * *$ & $1.000 * *$ & 1 \\
\hline
\end{tabular}

$* *=$ significant at $.01 ; *=$ at .05 level; $\mathrm{bD}=$ bulk density; $\mathrm{SMC}=$ soil moisture content; WHC $=$ water holding capacity; $\mathrm{TN}=$ Total nitrogen; $\mathrm{P}=$ phosphorous; $\mathrm{K}=$ potassium; $\mathrm{OM}=$ organic matter; $\mathrm{OC}=$ organic carbon

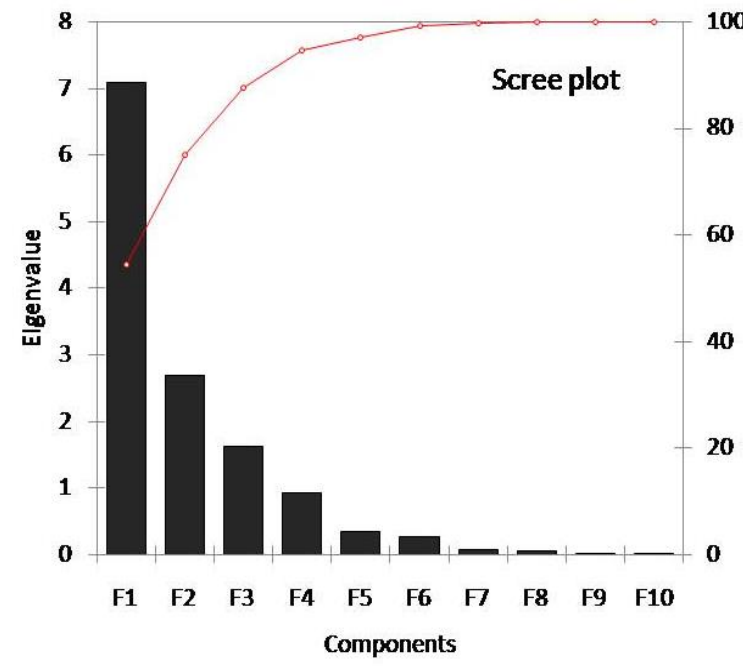

Figure 5. Scree plot showing the eigen value generated from PCA for the soil quality indicators.

\section{Soil Quality Index (SQI)}

SQI depicted that the soil quality was preferable at HA while it gradually decreased towards lower altitudes as HA (0.93) > MA (0.90) > LA (0.83) > VLA (0.77), among size classes the SQI showed that the small sized (0.98) AGEs were admirable and SQI significantly decreased with each successive season (rainy> winter> summer) (Figure 7). Peraza et al. (2017) studied the SQI of agricultural Valley in Culiacan and reported the range from 0.54 to 0.76 and classified under medium and high-quality soil and defined that the SQI values between 0.8 and 1.0 considered as very high-quality soils, while the values between 0.0 and 0.19 considered as very low-quality soils. An appropriate understanding of the soil qualities in those regions could mean the implementation of best management strategies for soils, which in return, would result in better productivity and greater yields. At the same time, these studies could contribute to the conservation and rational utilization of natural resources.

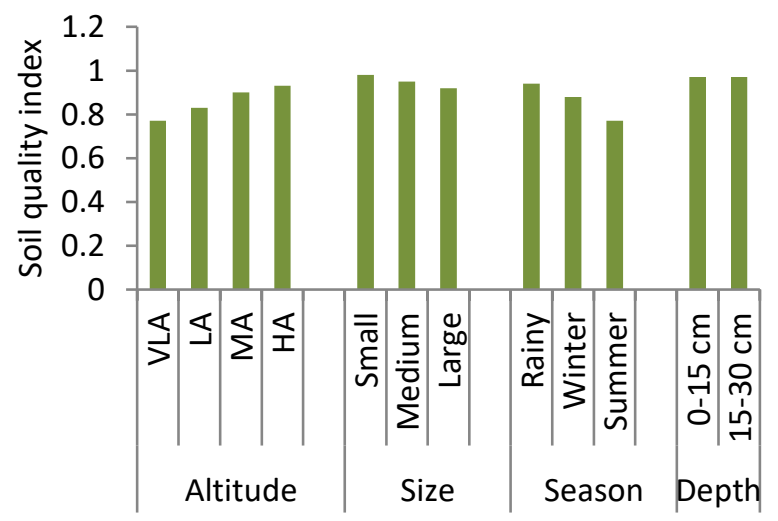

Figure 7. Soil Quality Index representing the effect of altitude, size, season and depth on all soil properties. $\mathrm{VLA}=$ very low altitude; $\mathrm{LA}=$ low altitude; $\mathrm{MA}=\mathrm{mid}$ altitude; $\mathrm{HA}=$ high altitude 


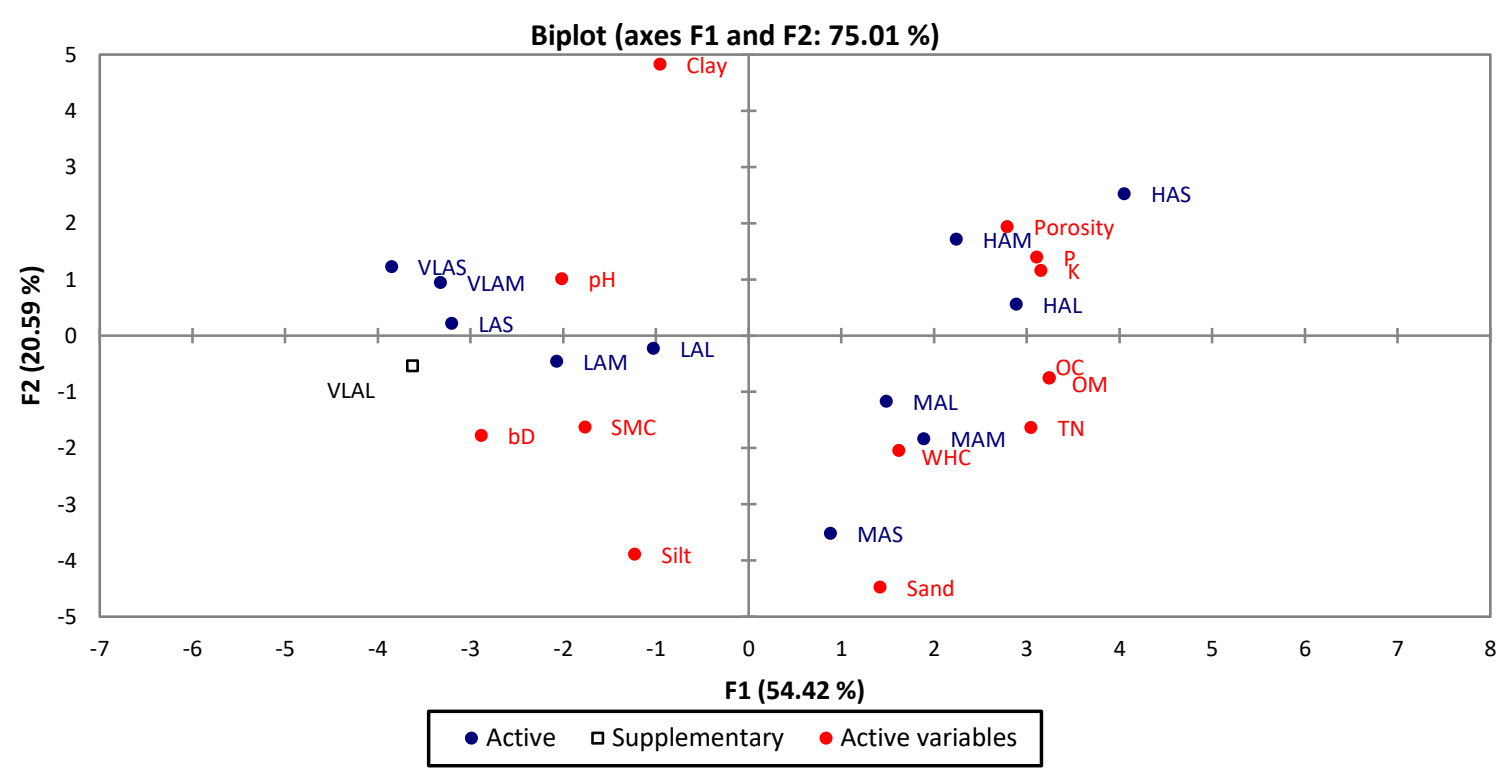

Figure 6. Principal component analysis (PCA) of soil quality indicators. (HAS, HAM, HAL- small, medium, large agroecosystems at high altitude; MAS, MAM, MAL- small, medium, large agroecosystems at mid altitude; LAS, LAM, LAL- small, medium, large agroecosystems at low altitude; VLAS, VLAM, VLAL- small, medium, large agroecosystems at very low altitude; $\mathrm{bD}=$ bulk density; $\mathrm{SMC}=$ soil moisture content; $\mathrm{WHC}=$ water holding capacity; $\mathrm{TN}=$ Total nitrogen; $\mathrm{P}=$ phosphorous; $\mathrm{K}=$ potassium; $\mathrm{OM}=$ organic matter; $\mathrm{OC}=$ organic carbon

Table 8. Factor loadings of different soil parameters

\begin{tabular}{llll}
\hline & F1 & F2 & F3 \\
\hline Sand (\%) & 0.421 & $\mathbf{- 0 . 8 1 7}$ & -0.106 \\
Silt $(\%)$ & -0.363 & $\mathbf{- 0 . 7 0 9}$ & -0.481 \\
Clay $(\%)$ & -0.283 & $\mathbf{0 . 8 8 2}$ & 0.314 \\
bD $\left(\mathrm{g} \mathrm{cm}^{-3}\right)$ & $\mathbf{- 0 . 8 5 5}$ & -0.324 & 0.293 \\
SMC (\%) & -0.523 & -0.296 & $\mathbf{0 . 7 3 1}$ \\
WHC $(\%)$ & 0.482 & -0.372 & $\mathbf{0 . 6 7 3}$ \\
Porosity $(\%)$ & 0.828 & 0.355 & -0.295 \\
pH & -0.597 & 0.184 & 0.072 \\
TN $(\%)$ & $\mathbf{0 . 9 0 5}$ & -0.299 & 0.109 \\
P $(\%)$ & $\mathbf{0 . 9 2 4}$ & 0.255 & -0.058 \\
K $(\%)$ & $\mathbf{0 . 9 3 7}$ & 0.212 & 0.199 \\
OM $(\%)$ & $\mathbf{0 . 9 6 3}$ & -0.137 & 0.167 \\
OC $(\%)$ & $\mathbf{0 . 9 6 3}$ & -0.137 & 0.168 \\
\hline
\end{tabular}

\section{CONCLUSION}

This study demonstrated that the altitudinal variations had a significant impact on certain physico-chemical properties of soil in agroecosystems. Physical properties of soils were also significantly affected by size differences of agroecosystems while chemical properties remain unaffected. It has been reported that $\mathrm{TN}$, OC, and OM were negatively correlated with seasons as rainy> winter > summer. Bulk density and SMC showed a significant positive correlation while porosity showed a significant negative correlation with depth. The analysis of principal components clearly depicted the importance of all parameters of soil quality. Overall results concluded that the soil qualities of small sized AGEs at HA were highly appreciable during rainy season. To harness maximum benefits from agricultural ecosystems the traditional practices (adding compost, dung manure, animal waste, crop residues, forest floor biomass, etc.) being performed by peasants of high and mid altitudes. Suitable management practices of mid and high altitudes reflected as the high fertility of the soil in those regions which must be adhered to by the farm managers of low and very low altitudes to sustain their livelihood as well as the health of mother earth.

\section{ACKNOWLEDGEMENT}

The response and cooperation of villagers during fieldwork is duly acknowledged by authors. This research did not receive any grant from funding agencies.

\section{REFERENCES}

Adigun, M.O., Akinbola, G.E., Olaleye, A.O. and Obuh, J. 2008. Variability of soil properties across planted fallows under earthworm casts on an alfisols in South Western Nigeria. World Journal of Agricultural Sciences 4: 435-441.

Altieri, M.A., Funes-Monzote, F.R. and Petersen, P. 2012. Agroecologically efficient agricultural systems for smallholder farmers: contribution to food security. Agronomy for Sustainable Development, 32: 1-13. 
Azam, M.S., Shafiquzzaman, M., Mishima, I. and Nakajima, J. 2009. Arsenic release from contaminated soil in natural field conditions. Journal of Scientific Research, 1: 258-269.

Bargali, K., Manral, V., Padalia, K., Bargali, S.S., and Upadhyay, V.P. 2018. Effect of vegetation type and season on microbial biomass carbon in Central Himalayan forest soils, India. Catena, 171: 125-135.

Bargali, S.S., Shukla, K., Singh, L., Ghosh, L., Lakhera and M. L. 2015. Leaf litter decomposition and nutrients dynamics in four tree species of dry deciduous forest. Tropical Ecology, 56: 191-200.

Bhatt, H., Husain, M., Rathore, J.P. and Sah, V.K. 2017. Bioremediation of problematic soils through agroforestry practices. Journal of Pharmacognosy and Phytochemistry, 6(5): 2044-2048.

Black, C.A. 1965. Methods of soil analysis, Part 2. Chemical and microbial properties. Madison Wisconsin. American Society of Agronomy, 771-512.

Burton, M., Allard, P., Mure, F. and Spina, A. 2007. Magmatic gas composition reveals the source depth of slug-driven strombolian explosive activity. Science, 317: 227-230.

Chaudhari, P.R., Ahire, D.V., Ahire, V.D., Chkravarty, M. and Maity, S. 2013. Soil bulk density as related to soil texture, organic matter content and available total nutrients. International Journal of Scientific and Research Publications, 3: 1-8.

Climate Uttarakhand, 2018. Temperature, climate graph. Climate-data.org. https://en.climatedata.org/asia/india/uttarakhand-763/.

Conway, G.R. 1987. The properties of agroecosystems. Agricultural Systems, 24(2): 95-117.

Curell, M.J., Han, D.M., Chen, Z.Y. and Cartwright, I. 2012. Sustainability of groundwater usage in northern China: dependence on palaeowaters and effects on water quality, quantity and ecosystem health. Hydrological Processes, 26: 4050-4066

Gairola, S., Sharma, C.M. Ghildiyal, S.K. and Suyal, S. 2012. Regeneration dynamics of dominant tree species along an altitudinal gradient in a moist temperate valley slopes of the Garhwal Himalaya. Journal of Forestry Research, 23: 53-63.

Garhwal, R.S., Qureshi, F.M. and Giri, J.D. 2013. Characteristics and classification of soils of Sirohi district of Rajasthan. Agropedology, 23: 8-15.

Garten, C.T., Post, W.M., Hanson, P.J. and Cooper, L.W. 1999. Forest Soil Carbon Inventories and Dynamics along an Elevation Gradient in the
Southern Appalachian Moun-tains. Biogeochemistry, 45: 115-145.

Groffman, P.M., Hardy, J.P., Fisk, M.C., Fahey, T.J. and Driscoll, C.T. 2009. Climate variation and soil carbon and nitrogen cycling processes in a northern hardwood. Forest Ecosystem, 12: 927-943.

He, X., Hou, E., Liu, Y. and Wen, D. 2016. Altitudinal patterns and controls of plant and soil nutrient concentrations and stoichiometry is sub tropical China. Scientific reports. 6: 1-9.

Indian standard, 1965. Indian standard: 2720, part IV: Grain size analysis. Indian Standard Institute, New Delhi.

Jackson, M.L. 1958. Soil Chemical Analysis. Prentice Hall, Inc. Englewood Clift, NJ.

Jaman, M.S., Islam, M.S., Jamil, M. and Hossain, M.F. 2016. Soil organic carbon and tree density in homegardens of Rangpur district, Bangladesh. International Journal of Plant and Soil Science, 13: 1-10.

Jose, S. and Bardhan, S. 2012. Agroforestry for biomass production and carbon sequestration: an overview. Agroforestry Systems, 86: 105111.

Joshi, G. and Negi, G.C.S. 2015. Physico-chemical properties along soil profiles of two dominant forest types in Western Himalaya. Current Science, 109: 798-803.

Keller, T. and Håkansson, I. 2009. Estimation of reference bulk density from soil particle size distribution and soil organic matter content. Geoderma, 154: 398- 406

Kjeldahl, J. 1883. New Method for the determination of Nitrogen. Chemistry News, 48: 101-102.

Kumar, B.M. (2000). Ailanthus triphysa in the homegardens of Kerala, India: occurrence, basal area, average standing stock of wood and diameter structure. Indian Journal of Agroforestry, 2: 49-52.

Mariappan, V.E., Rajan, S. and John, P. 2018. Environmental analysis of quarry site in Tamilnadu. Indian Journal of Science Research, 17: 37-45.

Morisada, K., Ono, K. and Kanomata, H. 2004. Organic carbon stocks in forest soils in Japan. Geoderma, 119: 23-32.

Miller, G.T. 2007. Living in the Environment.13 $3^{\text {th }}$ edition.

Misra, R. 1968. Ecology Work Book. Oxford Publishing Company, Kolkata.

Murphy, C.A., Foster, B.L., Ramspott, M.E. and Price, K.P. 2004. Grassland management effects on soil bulk density. Transactions of the Kansas Academy of Science, 107: 45-54.

Ololade, I.A., Ajayi, I.R., Gbadamosi, A. E., Mohammed, O.Z. and Sunday, A.G. 2010. A study on effects of soil physico- chemical 
properties on cocoa production in Ondo state. Modern Applied Science, 4.

Olsen, S.R., Cole, C.V., Watanabe, F.S. and Dean, L.A. 1954. Estimation of available phosphorus in soils by extraction with Sodium bicarbonate. Department of Agriculture Circular. USA. 939.

Panthi, J. 2010. Altitudinal Variation of Soil Fertility: A Case Study from Langtang National Park. M.Sc thesis. Central Department of Environmental Science, Tribhuvan University Kathmandu, Nepal.

Paudel, S. and Sah, J.P. 2003. Physiochemical characteristics of soil in tropical sal (Shorea robusta Gaertn.) forests in eastern Nepal. Himalayan Journal of Sciences, 1: 107-110.

Peach, K. and Tracy, M.B. (1956). Modern Methods of Plant Analysis. 1, Springer-Verlag, Berlin, Heidelberg, 542.

Peraza, J.G.R., Gasca, E.P., Corrales, R.L., Medina, J.R., Terrones, Y.B., Sosa, L.E.A., Mata, A.E. and Enciso, T.O. 2017. Robust soil quality index for tropical soils influences by agricultural activities. Journal of Agricultural Chemistry and Environment, 6: 199-221.

Piper, C.S. 1950. Soil and Plant Analysis. The University of Adelaide. Academic press, New York.

Rhanor, T. 2013. Topographic position and land cover effects on soil organic carbon distribution of loess-veneered hillslopes in the central United States. M.Sc Dissertation. Southern Illinois University Carbondale.

Saha S., Rajwar, G.S. and Kumar, M. 2018. Soil properties along altitudinal gradient in Himalayan temperate forest of Garhwal region. Acta Ecologica Sinica, 38: 1-8.

Sanjay, K., Munesh, K. and Mehraj, A.S. 2010. Effect of Altitudes on Soil and Vegetation Characterstics of Pinus roxburghii Forest in Garhwal Himalaya. Journal of Advanced Laboratory Research in Biology, 1.

Schmidt, M.W., Torn, M.S., Abiven, S., Dittmar, T., Guggenberger, G., Janssens, I.A., Kleber, M., et al. 2011. Persistence of soil organic matter as an ecosystem property. Nature, 478: 49-56.

Schroth, G., G. A. B. da Fonseca., C. A. Harvey., C. Gascon., H. L. Vasconcelos. and A. M. N. Izac, eds., 2004. Agroforestry and biodiversity conservation in tropical landscapes. Washington, DC: Island Press.

Semwal, S. 2006. Studies on phytosociology, Diversity patterns and competition along an altitudinal gradient in a part of lesser Himalaya in Garhwal, Uttarakhand (D. Phill. Thesis), HNB Garhwal University, Srinagar, Uttarakhand, India.
Shah, A., Niaz, A., Ullah, N., Rehman, A., Akhlaq, M., Zakir, $\mathrm{M}$ and Khan, M.S. 2013. Comparative study of heavy metals in soil and selected medicinal plants. Journal of Chemistry, 1-5.

Shahi, C. 2020. Agroecosystems of Kumaun Himalaya: Ecology, Productivity, Nutrient Dynamics and Energy Budget.Ph. D Thesis, Kumaun University, Nainital

Shahi C., Bargali S.S., Bargali, K. 2019. Effects of size and altitude on plant diversity in agroecosystems of Kumaun Himalaya, India. Eds. Richa Singh, Sharad Vaish, Vineeta Lal, Ragvendra Pratap Narayan. Shrinkhala Publishing House, Ayodhya (U.P). 38-51 pp.

Sinha, N.K. and Chopra, U. 2013. Cropping system effects on soil quality for three agroecosystems in India. Experimental Agriculture, 50: $321-342$.

Soil Science Society of America (SSSA), 2008. "Glossary of Soil Science Terms." www.soils.org/publications/ soils-glossary/.

Spohn, M., Klaus, K., Wanek, W. and Richter, A. 2016. Microbial carbon use efficiency and biomass turnover times depending on soil depth- implications for carbon cycling. Soil Biology and Biochemistry, 96: 74-81.

Su, Z.Y., Xiong, Y. M., Zhu, J.Y., Ye, Y. C., and Ye, M. 2006. Soil organic carbon content and distribution in a small landscape of Dongguan, South China. Pedosphere, 16: 10-17.

Takata, Y., Funakawa, S., Akshalov, K., Ishida, N. and Kosaki, T. 2007. Spatial prediction of soil organic matter in northern Kazakhstan based on topographic and vegetation information. Soil Science and Plant Nutrition, 53: 289-299.

Tsozué, D., Tamfuh, P.A. and Bonguen, S.M.N. 2015. Morphology, Physicochemical characteristics and land suitability in the western highlands of Cameroon. International Journal of Plant and Soil Science, 7: 29-44.

Upadhyaya, A.U., Arunachalam, K.A. and Arunachalam, K. 2003. Microbial biomass and physico- chemical properties of soils under the canopy of Bambusa balcooa Roxb. and Bambusa pallida Munro. Indian Journal of Soil Conservation, 31: 152-156.

Usman S., Singh, S.P., Rawat, Y.S. and Bargali, S.S. 2000. Fine root decomposition and nitrogen mineralization patterns in Quercus leucotrichophora and Pinus roxburghii forests in Central Himalaya. Forest Ecology and Management, 131: 191-199.

Vibhuti. 2018. Homegardens as a strategy for carbon sequestration: a case study from Kumaun 
Himalaya, India. Ph. D thesis. DSB Campus, Kumaun University, Nainital.

Walkley, A.E. and Black, J.A. 1934. An examination of the Degtiga Vett. Method for determining soil organic matter and proposed modification of the chromic acid titration method. Soil Science, 37: 29.

Wang, Y., Li, R., Li, D., Jia, X., Zhou, D., Li, J., et al. 2017. NIP1;2 is a plasma membrane-localized transporter mediating aluminum uptake, translocation, and tolerance in Arabidopsis. Proceedings of the National Academy of Sciences of the United States of America, 114: 5047-5052.
Wani, S. A., Najar, G. R., Akhter, F., Wani, M. S. and Mir, S.A. 2017. Altitudinal variations of soil physico-chemical properties in pear orchards of district Pulwama under temperate Jammu and Kashmir, India. International Journal of Chemical Studies, 5: 162-166.

Yao, M.K., Angui, P.K.T., Konate, S., Tondoh, J.E., Tano, Y., Abbadie, L. and Benest, D. 2010. Effects of land use types on soil organic carbon and nitrogen dynamics in Mid-West Cote d'Ivoire. European Journal of Scientific Research, 40: 211-222.

Zhang, S., Huang, Y., Shen, C., Ye, H. and Du, Y. 2012. Spatial prediction of soil organic matter using terrain indices and categorical variables as auxiliary information. Geoderma, 171: 35-43.

Citation: Shahi, C.; Bargali, S.S. and Bargali, K. 2021. Soil properties among Indian Central Himalayan agroecosystems as affected by altitude and size variations. International Journal of Agricultural and Applied Sciences, 2(1): 68-79. https://doi.org/10.52804/ijaas2021.218

Copyright: (c) Shahi et.al. 2021. Creative Commons Attribution 4.0 International License. IJAAS allows unrestricted use, reproduction, and distribution of this article in any medium by providing adequate credit to the author(s) and the source of publication. 